\title{
Cancellation of exemption from medical fees.
}

Engelchin-Nissan $\mathbf{E}^{1^{*}}$, Kokia $\mathbf{E}^{1}$, Tsamir $\mathbf{J}^{2}$, Kertes $\mathbf{J}^{2}$

${ }^{1}$ Department of Economics, Ramat Gan College, ISRAEL

${ }^{2}$ Department of Economics, Maccabi Health Services, ISRAEL

\begin{abstract}
Background: The collection of medical fees is an effective way of reducing costs in health systems. This deductible increases the price per unit per insured from zero to the deductible level, thereby reducing the quantity requested and reducing the moral risk. The deductible raises serious concerns that are described in the professional literature and are more disturbing in public health systems based on justice and fairness, such as the Israeli one introduced in 1995. In 2003 there was a change in the definition of policyholders entitled to exemption from medical fees.
\end{abstract}

The aims of the study: Estimation of the change in the consumption of medical services for individuals whose eligibility for exemption has been changed.

Populations and samples: The study population was divided into three sub-populations: Stop receiving the benefit, continue to receive the benefit and Control group: Members who did not have an economic benefit during the entire study period.

Data analysis: 1. Comparison of the average visits before and after was examined using a T-test.

2. In the multivariate model, we used a Poisson hierarchical model, GEE*, because of repeated measurements for each patient, while monitoring the variables: gender, age, sector, health status, and SES.

3. The comparison of the average cost was performed using a variance analysis and the post hoc tests between the three groups were corrected according to Scheffe.

Results: The results are very sharp in their significance. In both control groups, those who continued the exemption and those who had never been exempted from service consumption increased. In contrast, the consumption of medical services for policyholders for whom the exemption was discontinued decreased.

Conclusion: The enactment of the National Health Insurance Law in 1995 was a dramatic social statement by the government, which took responsibility for providing medical care to the general public, regardless of the economic ability of the patients. The law included very important statements about an ideal society, and at the outset defined it as based on justice, equality and mutual aid. Despite the promises embodied in the law, its full implementation and principles were not fully realized and the collection of medical fees is an example. The law included very important statements about an ideal society, and at the outset defined it as based on justice, equality and mutual aid. Despite the promises embodied in the law, its full implementation and principles were not fully realized and the collection of medical fees is an example..

Keywords: Medical fees, Consumption of health services.

\section{Introduction}

\section{Self-participation-background}

In fully competitive markets, the optimum point of consumption is the point at which the marginal expenditure of the producer meets the marginal benefit of consumers. Adam Smith in his book "Wealth of Nations" used the term "invisible hand" as a metaphor for the subject. In the health markets, where consumers do not pay for the services provided, since the payments are paid by a third party, their tendency to consume health services rises and therefore this optimum is not attainable as a free market [1]. The goal of self-participation is to increase the efficiency of the system in the sense of preventing moral hazard and wasting resources [2]. This deductible increases the price per unit per insured from zero to the deductible level, thereby reducing the quantity requested and reducing the moral risk. The deductible raises serious concerns that are described in the professional literature and are more disturbing in public health systems based on justice and fairness, such as the Israeli one introduced in 1995. First, the collection of fees raises problems in the area of fairness and equality. Since the self-contributions are usually fixed, they are a regenerative source of funding for the health system, i.e., the percentage of self-participation from income declines with the increase in income [3].These payments mainly affect populations at low income levels, thereby eroding the principle of social solidarity embodied in the National Health Insurance 
Law. The great fear is, that self-participation will reduce not only unnecessary treatment, but will cause the insured, especially the poor, to give up the necessary medical treatment. Research shows that when populations do not use health care when they need it, their health will worsen [4]. In addition, since selfparticipation is paid for actual use, patients pay more than the healthy. Another claim that reinforces the claim of impairment is that the patients bear a double burden, in addition to their illness, which places them as weak in society [5]. Moreover, self-participation is not directed directly at the right players: decision-making on appropriate and appropriate treatment relies mainly on doctors rather than patients [6]. Researchers further emphasize that while the payment will reduce the phenomenon of moral hazard (A situation in which one party gets involved in a risky event knowing that it is protected against the risk and the other party will incur the cost) among the population group at the low socio-economic level, among the rich population the fee will not reduce the consumption of unnecessary services [7]. The international experience of using payments as a tool to restrain expenditure, as well as the Israeli experience, indicates that the effect of payments is limited to the short term, may reduce demand even if necessary, and may divert demand from service areas that are subject to payment to other free service areas. In most countries there is a system of discounts and payment ceilings for self-participation in the elderly and chronically ill. In recent years, more and more researchers and policymakers have argued that the accepted self-participation should be replaced by a system of differential self-participation according to utility or medicine: Health services and drugs that contribute significantly to health (such as preventive medical services) should be subject to minimal deductible and services and medicines with little utility-to impose high self-participation [8].

\section{International experience}

Van de Voore and Garattini examined the method of selfparticipation in six different Western countries: In countries with national health insurance at a regional level-like England, Spain and Italy and in countries with health insurance according to Bismarck's theory-France, Germany and the Netherlands. In the Netherlands, the deductible method is used, in Italy the copayment method, and in Germany the coinsurance method. France and Spain combine the approaches of coinsurance and copayment. All six countries have a system of granting exemptions to different population groups. For example: children, pregnant women, disabled persons, pensioners and individuals who are ill of one of 30 different chronic diseases.

\section{The Israeli history of self-participation in health}

The National Health Insurance Law, enacted in 1995, allowed health funds to charge health services such as primary and secondary medical fees. However, with the understanding that these fees could discriminate against low socio-economic groups, groups were set up to qualify for discounts or exemptions from payments for medical services - visits to specialist physicians or payments to medicines. The following groups are entitled to discounts from visits to specialist physicians: recipients of allowances from the National Insurance Institute (General disability pension, mobility allowance for disabled child, oldage pension for persons paid before disability pension, income support and food support) and "Kollel" students, their spouse and children who receive an income support benefit from the Ministry of Religious Affairs. In Israel there are 4 HMOs. Table 1 reflects the number of insured individuals entitled to an exemption from paying a fee in each fund.

Within the framework of the Law for the Economic Recovery, the assumptions given in the past and the visits to specialist doctors have been cancelled for the recipients of income support benefits up to age 65 , for recipients of alimony payments and for the recipients of income support from the Ministry of religious Affairs.

The current study is intended to examine how the Ministry of Finance's decision affected the 90,000 residents who were entitled to an exemption and as of 2003 are no longer entitled to this exemption.

\section{The Aims of the Study}

Estimation of the change in the consumption of medical services for individuals whose eligibility for exemption has been changed. The study population was divided into three sub-populations: Stop receiving the benefit, continue to receive the benefit and Control group: Members who did not have an economic benefit during the entire study period. Most studies have shown that a change in the amount of medical fees collected from policyholders changes the amount of medical services they consume.

\section{Populations, Samples and Statistics}

1. Comparison of the average visits before and after was examined using a T-test (Table 2).

Table 1. Insures entitled to discounts from payments for health services by population groups, 2002.

\begin{tabular}{|c|c|c|c|c|c|}
\hline $\begin{array}{c}\text { Population } \\
\text { Group }\end{array}$ & $\begin{array}{c}\text { Clalit } \\
\text { Health } \\
\text { Care } \\
\text { Services }\end{array}$ & $\begin{array}{c}\text { Maccabi } \\
\text { Health } \\
\text { Care } \\
\text { Services }\end{array}$ & $\begin{array}{c}\text { Meuhedet } \\
\text { Health } \\
\text { Care } \\
\text { Services }\end{array}$ & $\begin{array}{c}\text { Leumit } \\
\text { Health } \\
\text { Care } \\
\text { Services }\end{array}$ & Total \\
\hline $\begin{array}{c}\text { Recipients of } \\
\text { old-age and } \\
\text { survivors' } \\
\text { pension } \\
\text { with income } \\
\text { supplement }\end{array}$ & 210,814 & 59,584 & 21,560 & 34,280 & 326,238 \\
\hline $\begin{array}{c}\text { Recipients } \\
\text { of general } \\
\text { disability } \\
\text { pension }\end{array}$ & 231,167 & 45,181 & 21,049 & 29,795 & 327,192 \\
\hline $\begin{array}{c}\text { Recipients } \\
\text { of income } \\
\text { maintenance } \\
\text { benefit up to } \\
\text { age 65 }\end{array}$ & 229,086 & 58,894 & 27,700 & 39,927 & 355,607 \\
\hline $\begin{array}{c}\text { Recipients } \\
\text { of alimony } \\
\text { payments }\end{array}$ & 32,487 & 13,578 & 6,265 & 7,164 & 59,494 \\
\hline $\begin{array}{c}\text { Recipients } \\
\text { of Income } \\
\text { Support from } \\
\text { the Ministry } \\
\text { of Religious } \\
\text { Affairs }\end{array}$ & 15,770 & 17,836 & 24,413 & 21,074 & 79,093 \\
\hline & & & & & \\
\hline
\end{tabular}


Table 2. Characteristics of the three research groups.

\begin{tabular}{|c|c|c|c|c|}
\hline $\mathbf{p}$ & control group & The exemption continues & $\begin{array}{c}\text { The exemption was } \\
\text { canceled }\end{array}$ & WOMEN \\
\hline$<0.0001$ & $2379(50.1 \%)$ & $2164(48.7 \%)$ & $507(60.1 \%)$ & LOW SES \\
\hline$<0.0001$ & $620(13.1 \%)$ & $1442(32.5 \%)$ & $281(33.3 \%)$ & Average SES \\
\hline$<0.0001$ & $2599(54.8 \%)$ & $2633(59.3 \%)$ & $498(59 \%)$ & High SES \\
\hline$<0.0001$ & $1527(32.2 \%)$ & $365(8.2 \%)$ & $65(7.7 \%)$ & Arab sector \\
\hline$<0.0001$ & $204(4.3 \%)$ & $464(10.4 \%)$ & $69(8.2 \%)$ & Orthodox sector \\
\hline$<0.0001$ & $240(5.1 \%)$ & $317(7.1 \%)$ & $51(6 \%)$ & Age $0-18$ \\
\hline$<0.0001$ & $1011(21.6 \%)$ & $844(9.3 \%)$ & $344(40.8 \%)$ & Age $19-30$ \\
\hline$<0.0001$ & $366(7.8 \%)$ & $325(7.4 \%)$ & $91(10.8 \%)$ & Age 31-50 \\
\hline$<0.0001$ & $1470(31.4 \%)$ & $1378(31.5 \%)$ & $230(27.3 \%)$ & Age $51-65$ \\
\hline$<0.0001$ & $1690(36 \%)$ & $1682(38.4 \%)$ & $166(19.7 \%)$ & Age $66+$ \\
\hline
\end{tabular}

Table 3. Results of visits to primary physician. GEE-Generalized Estimating Equations.

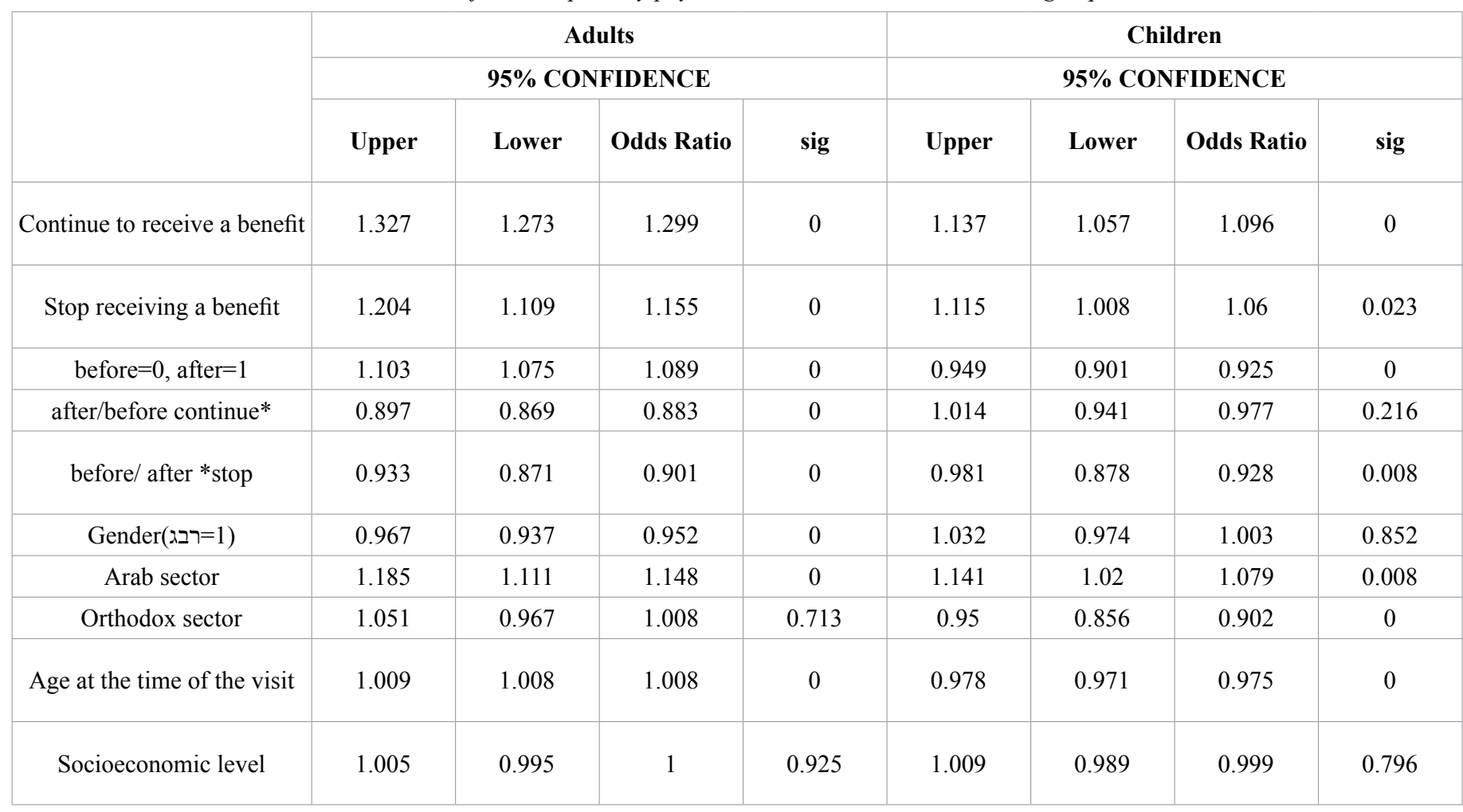

2. In the multivariate model, we used a Poisson hierarchical model, GEE*, because of repeated measurements for each patient, while monitoring the variables: gender, age, sector, health status, and SES.

${ }^{*}$ Generalized Estimating Equations.

3. The comparison with the average cost of each group was done by stratification for age (Each age group was examined separately). The comparison of the average cost was performed using a variance analysis and the post hoc tests between the three groups were corrected according to Scheffe (Table 3).

\section{Findings and Results}

In the age group of children there is a decrease in the number of uses for a primary physician visit even after monitoring background variables such as gender, Arab sector, Orthodox sector, age and socioeconomic cluster. The most significant decline was in the group that canceled the exemption from payment of fees $(14 \%)$. In the control groups, consumption also declined, but by a lower percentage: $9 \%$ for the group that did not cancel the exemption and $6 \%$ for the group that was never exempted (Figure 1).

In the group of children up to the age of 18 , the results are very sharp in their significance. In both control groups, those who continued the exemption and those who had never been exempted from service consumption increased by $5 \%$. In contrast, the consumption of medical services for policyholders for whom the exemption was discontinued decreased by $28 \%$ (Table 4 and Figure 2).

\section{Discussion and Conclusions}

The purpose of the deductible is to increase the efficiency of the system in the economic aspect of preventing unnecessary uses since they are provided free of charge. However, the deductible raises serious concerns about fairness and equality in the health system, since the collection of a fixed sum is a regressive tax that affects the population at a low socio- 


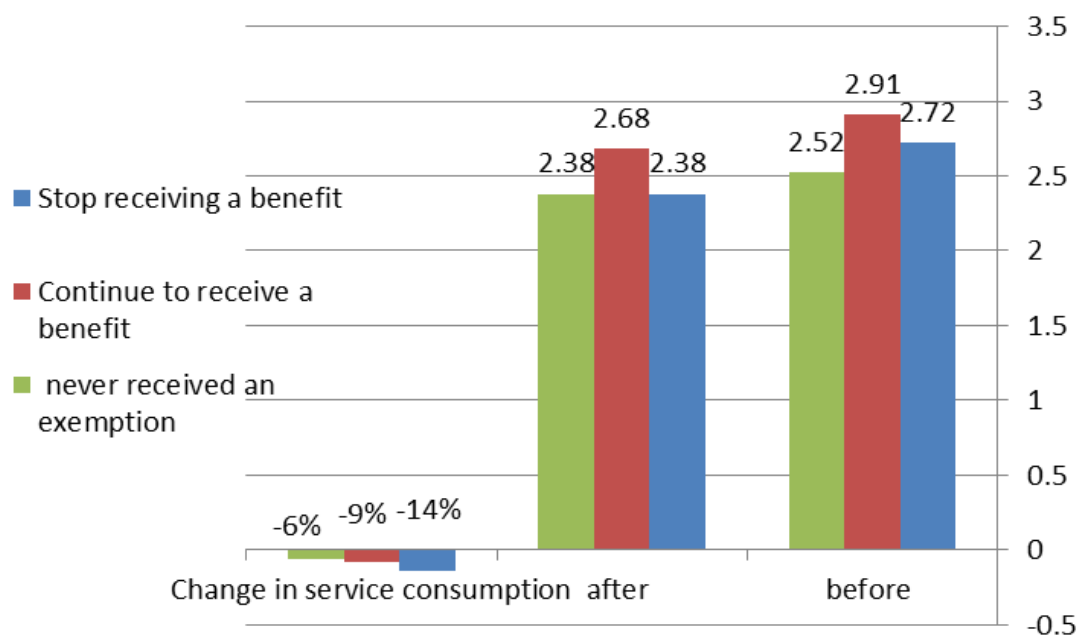

Figure 1. Children up to the age of 18 - Visits to primary care. All results are significant, $p<0.001, T$-test.

Table 4. Results of visits to a secondary physician. GEE-Generalized Estimating Equations.

\begin{tabular}{|c|c|c|c|c|c|c|c|c|}
\hline \multicolumn{4}{|c|}{ Adults } & \multicolumn{4}{|c|}{ Children } & \\
\hline \multicolumn{4}{|c|}{ 95\% CONFIDENCE } & \multicolumn{4}{|c|}{ 95\% CONFIDENCE } & \\
\hline Upper & Lower & Odds Ratio & sig & Upper & Lower & Odds Ratio & sig & \\
\hline 1.847 & 1.684 & 1.764 & 0 & 1.407 & 1.156 & 0 & 0 & Continue to receive a benefit \\
\hline 1.526 & 1.277 & 1.396 & 0 & 1.446 & 1.112 & 0 & 0.023 & Stop receiving a benefit \\
\hline 1.1 & 1.074 & 1.074 & 0 & 1.161 & 1.009 & 0.026 & 0 & before $=0$, after $=1$ \\
\hline 0.948 & 0888 & 0.917 & 0 & 1.085 & 0.894 & 0.76 & 0216 & after/before continue* \\
\hline 0.997 & 0.861 & 0.926 & 0 & 0.887 & 0.681 & 0 & 0.008 & before/ after *stop \\
\hline 0.968 & 0.896 & 0.931 & 0 & 1.232 & 1.068 & 0 & 0.852 & Gender(רבג=1) \\
\hline 1.088 & 0.908 & 0.994 & 0 & 1.004 & 0.719 & 0 & 0.008 & Arab sector \\
\hline 1.028 & 0.832 & 0.925 & 0.713 & 1.175 & 0.924 & 0.055 & 0 & Orthodox sector \\
\hline 1.021 & 1.017 & 1.019 & 0 & 1.026 & 1.01 & 0 & 0 & Age at the time of the visit \\
\hline 1.051 & 1.025 & 1.038 & 0.925 & 1.076 & 1.026 & 0 & 0.796 & Socioeconomic level \\
\hline
\end{tabular}

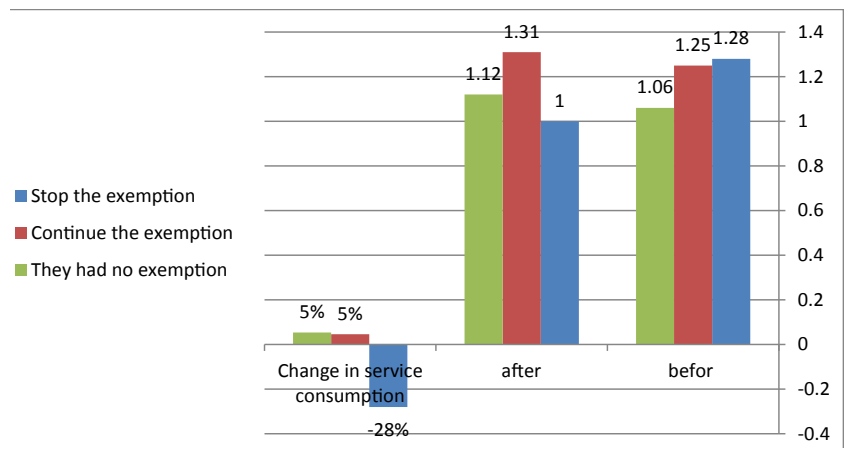

Figure 2. Children up to the age of 18-Visits to secondary medicine. All results are significant, $p<0.001$, T-test.

economic level. In order to try to minimize the negative impact of fees on the consumption of health services among the weaker population groups, it was decided to exclude a population group and grant them exemption from payment of fees This population consisted of five subgroups: Recipients of old age pension with income supplement, Recipients of Income Support from the Ministry of Religious Affairs, Recipients of alimony payments, Recipients of general disability pension and Recipients of income maintenance benefits up to age 65 . In the framework of the Law for the Recovery of the Israeli Economy, which was approved by the Knesset in 2003, assumptions for visits to specialist physicians were canceled for: recipients of income support benefits up to the age of 65 , recipients of alimony and recipients of income support from the Ministry of Religious Affairs. This study used a tool to detect, describe, and estimate the causal effect of causal intervention or treatment in a retrospective study. As noted, in 2003 there was a change in the definition of policyholders entitled to exemption from medical fees. The change in eligibility conditions took place at a distinct and clear time point for the members of the HMOs, which was arbitrarily determined without the ability of any of the fund's 
members to change it. Examining the variability of the values of the independent variables, Number of primary and secondary doctor visits on the timeline before and after the intervention, facilitate to disqualify alternative explanations and to estimate retrospectively the average effect of the intervention. On the practical level, this study confirms the economic theories that the elasticity of the demand curve among the poor is higher than among the rich and hence the imposition of self-participation reduces the demand for services more among those without financial means than those with financial means. The study points out unequivocally that the collection of medical fees from population groups at a low socioeconomic level reduces the use of essential health services. At the ideological level, we think that it should be noted that the principle of social solidarity inherent in the National Health Insurance Law has been impaired since these payments mainly affect populations at low income levels. The enactment of the National Health Insurance Law in 1995 was a dramatic social statement by the government, which took responsibility for providing medical care to the general public, regardless of the economic ability of the patients. The law included very important statements about an ideal society, and at the outset defined it as based on justice, equality and mutual aid. Despite the promises embodied in the law, its full implementation and principles were not fully realized and the collection of medical fees is an example.

\section{References}

1. Drummond M, Towse A. Is it time to reconsider the role of patient co-payments for pharmaceuticals in Europe? Eur $\mathrm{J}$ Health Econ. 2012;13:1-5.

2. Trivedi AN, Moloo H, Mor V. Increased ambulatory care copayments and hospitalizations among the elderly. N Engl J Med. 2010;362:320-8.

3. Manning WG, Newhouse JP, Duan N, et al. Health insurance and the demand for medical care: evidence from a randomized experiment. The American Economic Review. 1987;77:251-77.

4. Gemmill MC, Thomson S, Mossialos E. What impact do prescription drug charges have on efficiency and equity? Evidence from high-income countries. Int J Equity Health. 2008;7:12.

5. Freemantle N, Bloor K. Lessons from international experience in controlling pharmaceutical expenditure. I: Influencing patients. BMJ. 1996;312:1469-71.

6. Garattini L, van de Vooren K. Could co-payments on drugs help to make EU health care systems less open to political influence? Eur J Health Econ. 2013;14:709-13.

7. Moskop JC, Sklar DP, Geiderman JM, et al. Emergency department crowding, part 2-barriers to reform and strategies to overcome them. Ann Emerg Med. 2009;53:612-7.

8. Shmueli A. Basic Course in Health Economics for the Health Professionals, Magnes press. 2016. 